\title{
Combined effect of citrate and fluoride ions on hydroxyapatite nanoparticles
}

Lorenzo Degli Espostia, *, Alessio Adamianoa , Anna Tampieria, Gloria Belen RamirezRodriguez ${ }^{\mathrm{b}}$, Dritan Siliqic, Cinzia Gianninic ${ }^{c}$, Pavlo Ivanchenkod, Gianmario Martra ${ }^{\mathrm{d}}$, FengHuei Line,f, José Manuel Delgado-López ${ }^{\mathrm{b}}$, Michele Iafisco ${ }^{\mathrm{a}, *}$

anstitute of Science and Technology for Ceramics (ISTEC), National Research Council (CNR), Via Granarolo 64, 48018 Faenza (Italy)

bDepartment of Inorganic Chemistry, University of Granada, Av. Fuente Nueva, s/n, 18071, Granada (Spain)

'Institute of Crystallography (IC), National Research Council (CNR), Via Amendola 122/0, 70126 Bari (Italy)

${ }^{\mathrm{d}}$ Department of Chemistry and Interdepartmental Centre "Nanostructured Interfaces and Surfaces-NIS”, University of Torino, Via P. Giuria 7, 10125, Torino (Italy)

eDepartment of Biomedical Engineering, National Taiwan University, 10617 Taipei (Taiwan)

fInstitute of Biomedical Engineering and Nanomedicine, National Health Research Institutes, Keyan Road 35, 35053 Miaoli (Taiwan)

Authors for correspondence: Dr. Michele Iafisco, Ph. D.

Institute of Science and Technology for Ceramics (ISTEC) National Research Council (CNR),

Via Granarolo 64, 48018 Faenza (RA), Italy.

E-mail: michele.iafisco@istec.cnr.it

Lorenzo Degli Esposti, M. Sc.

Institute of Science and Technology for Ceramics (ISTEC)

National Research Council (CNR),

Via Granarolo 64, 48018 Faenza (RA), Italy.

E-mail: lorenzo.degliesposti@istec.cnr.it 
FT-IR spectra of citrate-HA. The IR-ATR spectra of the citrate-HA samples are reported in Figure S1B. All samples displayed a main broad band at $1030 \mathrm{~cm}^{-1}$ with shoulders at 1046 and $1075 \mathrm{~cm}^{-1}$ due to the triply degenerated anti-symmetric stretching mode of the apatitic $\mathrm{PO}_{4}$ groups $\left(\mathrm{V}_{3} \mathrm{PO}_{4}\right)$. Other features emerge at $961 \mathrm{~cm}^{-1}$ (symmetric stretching mode of the apatitic $\mathrm{PO}_{4}$ groups, $v_{1} \mathrm{PO}_{4}$ ) and at 603, 576 (as a shoulder) and $565 \mathrm{~cm}^{-1}$ (triply degenerated bending mode of the same groups, $v_{4} \mathrm{PO}_{4}$ ). Apatitic hydroxyl groups are evinced by a band at $631 \mathrm{~cm}^{-1}$ that is due to $\mathrm{OH}^{-}$librational modes [1]. The presence of traces amounts of carbonate ions is revealed by the presence of a very weak B-type carbonate substitution $\left(\mathrm{CO}_{3}\right.$ occupying $\mathrm{PO}_{4}$ sites $)$ band at $873 \mathrm{~cm}^{-1}$ [2].
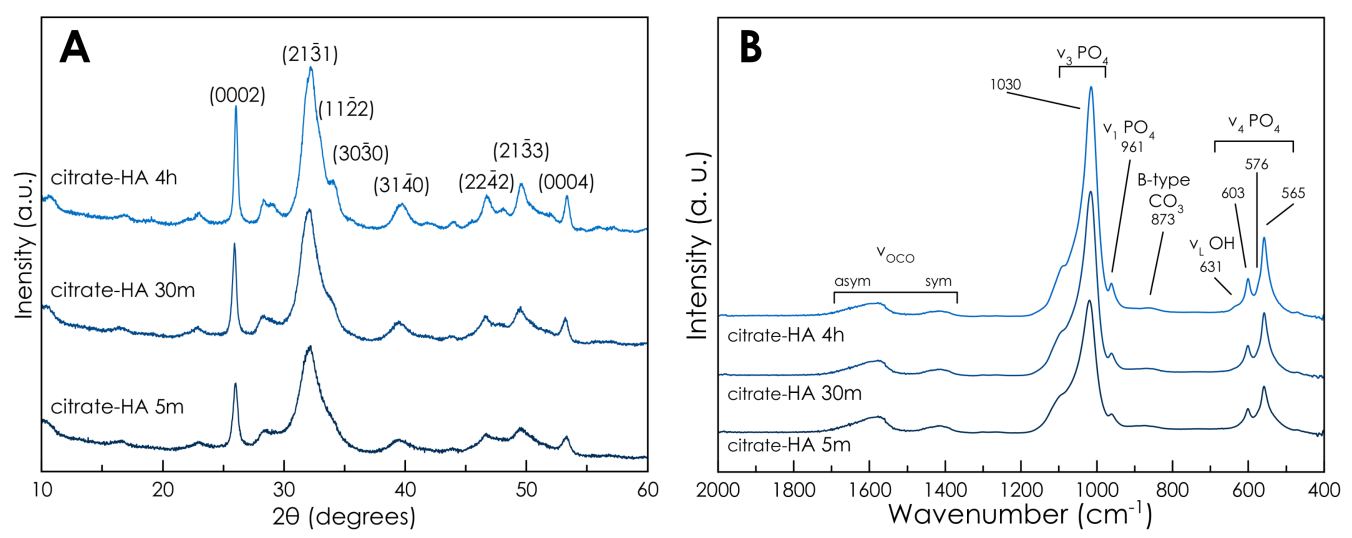

Figure S1. (A) PXRD diffractograms of citrate-HA 5m, citrate-HA 30m, and citrate-HA 4h. (B) FT-IR spectra of citrate-HA 5m, citrate-HA 30m, and citrate-HA $4 \mathrm{~h}$.
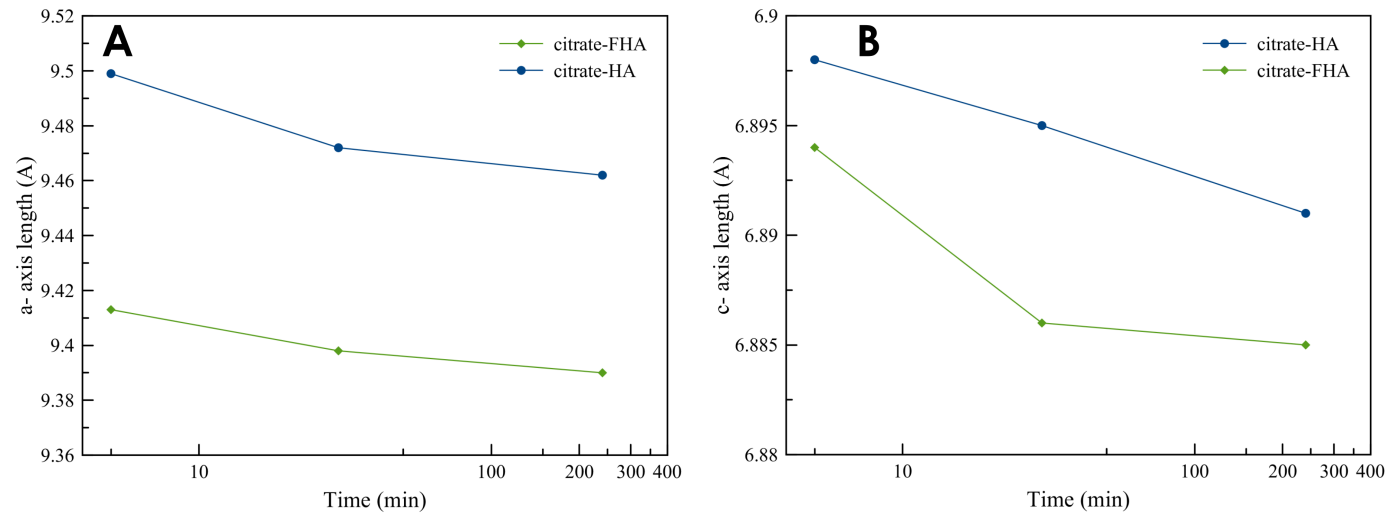

Figure S2. Plot as a function of the maturation time of (A) $a$ cell axis, (B) $c$ cell axis of citrate-FHA and citrateHA. 
Table S1. Cell parameters and crystal domain of citrate-HA samples.

\begin{tabular}{cccccc}
\hline Sample & $\begin{array}{c}a-b \\
\text { cell axes }(\AA)\end{array}$ & $\begin{array}{c}c \\
\text { cell axis }(\AA)\end{array}$ & $\mathrm{D}_{(0002)}(\mathrm{nm})$ & $\mathrm{D}_{(31-40)}(\mathrm{nm})$ & $\mathrm{D}_{(0002)} / \mathrm{D}_{(31-40)}$ \\
\hline Citrate-HA 5m & 9,499 & 6,898 & $21,6 \pm 0,5$ & $5.5 \pm 0,4$ & 3,9 \\
Citrate-HA 30m & 9,472 & 6,895 & $28,6 \pm 0,5$ & $6,3 \pm 0,7$ & 4,3 \\
Citrate-HA 4h & 9,462 & 6,891 & $42,9 \pm 0,5$ & $7.3 \pm 0,6$ & 5,9 \\
\hline
\end{tabular}
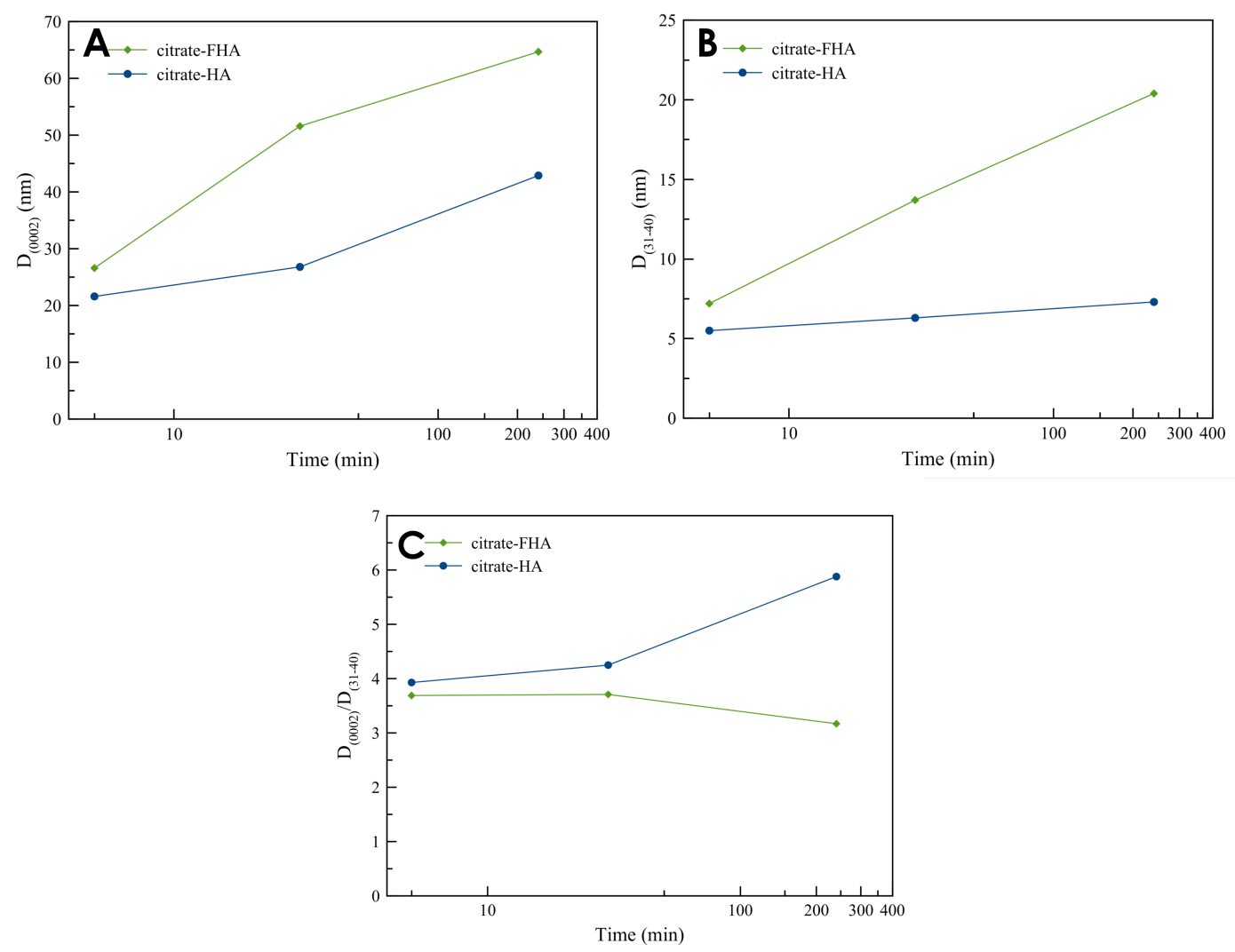

Figure S3. Plot as a function of the maturation time of $(A) D_{(0002)}$ crystal domain, $(B) D_{(31-40)}$ crystal domain and (C) $\mathrm{D}_{(0002)} / \mathrm{D}_{(31-40)}$ ratio of citrate-FHA and citrate-HA.

Table S2. Chemical composition of citrate-HA samples.

\begin{tabular}{cccccc}
\hline Sample & $\mathrm{Ca} / \mathrm{P}^{\mathrm{a}}(\mathrm{mol})$ & $\mathrm{Fb}^{\mathrm{b}}(\% \mathrm{wt})$ & Citratec $\left.^{\mathrm{c}} \% \mathrm{wt}\right)$ & Carbonate $^{\mathrm{c}}(\% \mathrm{wt})$ & 弓-Potential $(\mathrm{mV})$ \\
\hline Citrate-HA 5m & $1,54 \pm 0,02$ & - & $4,8 \pm 0,3$ & $1,4 \pm 0,2$ & $-13.1 \pm 0.4$ \\
Citrate-HA 30m & $1,54 \pm 0,02$ & - & $3,2 \pm 0,3$ & $0,8 \pm 0,1$ & $-12.4 \pm 0.4$ \\
Citrate-HA 4h & $1,53 \pm 0,01$ & - & $2,6 \pm 0,2$ & $1,2 \pm 0,1$ & $-9.3 \pm 0.4$ \\
\hline
\end{tabular}

(a) Quantified by ICP-OES; (b)Quantified by fluoride ion electrode; (c)Quantified by TGA. 
Thermogravimetric analysis. Thermogravimetric curves and their first derivatives of all the samples mainly shows four weight losses (Figure S4): (i) from room temperature to $200^{\circ} \mathrm{C}$ due to the adsorbed water, (ii) from $200^{\circ} \mathrm{C}$ to $400^{\circ} \mathrm{C}$ related to structural water, (iii) from 400 to $600^{\circ} \mathrm{C}$ due to the citrate, and (iv) from 600 to $1000^{\circ} \mathrm{C}$ corresponding to the carbonate ions [3].

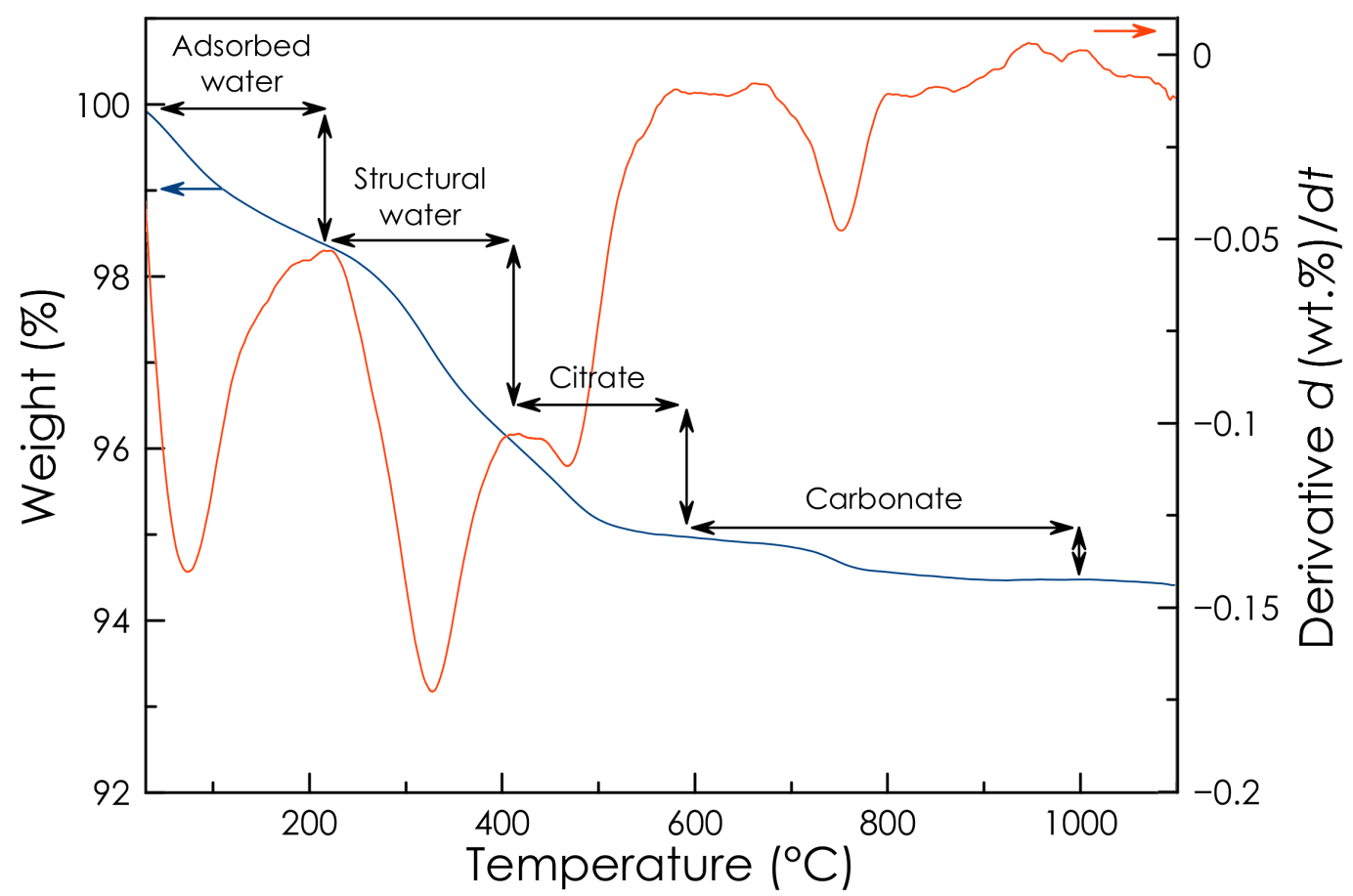

Figure S4. TGA and DTG curve of citrate-FHA 4h. The TGA curves of the other samples have the same profile. 
Raman spectroscopy. Figure S5A-B shows the Raman spectra of the samples. The most intense peak appears at $960 \mathrm{~cm}^{-1}$, which corresponds to $v_{1} \mathrm{PO}_{4}$ mode. Other features from apatitic $\mathrm{PO}_{4}$ group emerge at $1042 \mathrm{~cm}^{-1}\left(v_{3} \mathrm{PO}_{4}\right), 586\left(v_{4} \mathrm{PO}_{4}\right)$ and 428 $\mathrm{cm}^{-1}\left(\mathrm{v}_{2} \mathrm{PO}_{4}\right)$. In the spectrum of both citrate-FHA and citrate-HA nanoparticles, very weak B-type carbonate bands appeared at $1070 \mathrm{~cm}^{-1}\left(v_{1} \mathrm{CO}_{3}\right)$ and at $1430 \mathrm{~cm}^{-1}$ $\left(\mathrm{v}_{2} \mathrm{CO}_{3}\right)$, confirming the data of IR-ATR spectra and chemical analysis [2]. Moreover, the Raman spectrum of citrate-HA samples exhibit an intense peak at $3570 \mathrm{~cm}^{-1}$ (Figure S5C-D) associated to the apatitic $\mathrm{vOH}$ mode. The intensity of this peak increases with maturation time. On the contrary, this band is not present in the spectrum collected for the citrate-FHA nanoparticles, further confirming that $\mathrm{OH}^{-}$ ions were completely replaced by fluoride ions. The bands at 2930 and $845 \mathrm{~cm}^{-1}$ are related to the $v \mathrm{CH}_{2}$ and the $\delta 0 \mathrm{CO}$ modes of citrate [4], respectively, and their relative intensity decreases with maturation time as observed in the IR-ATR spectra.
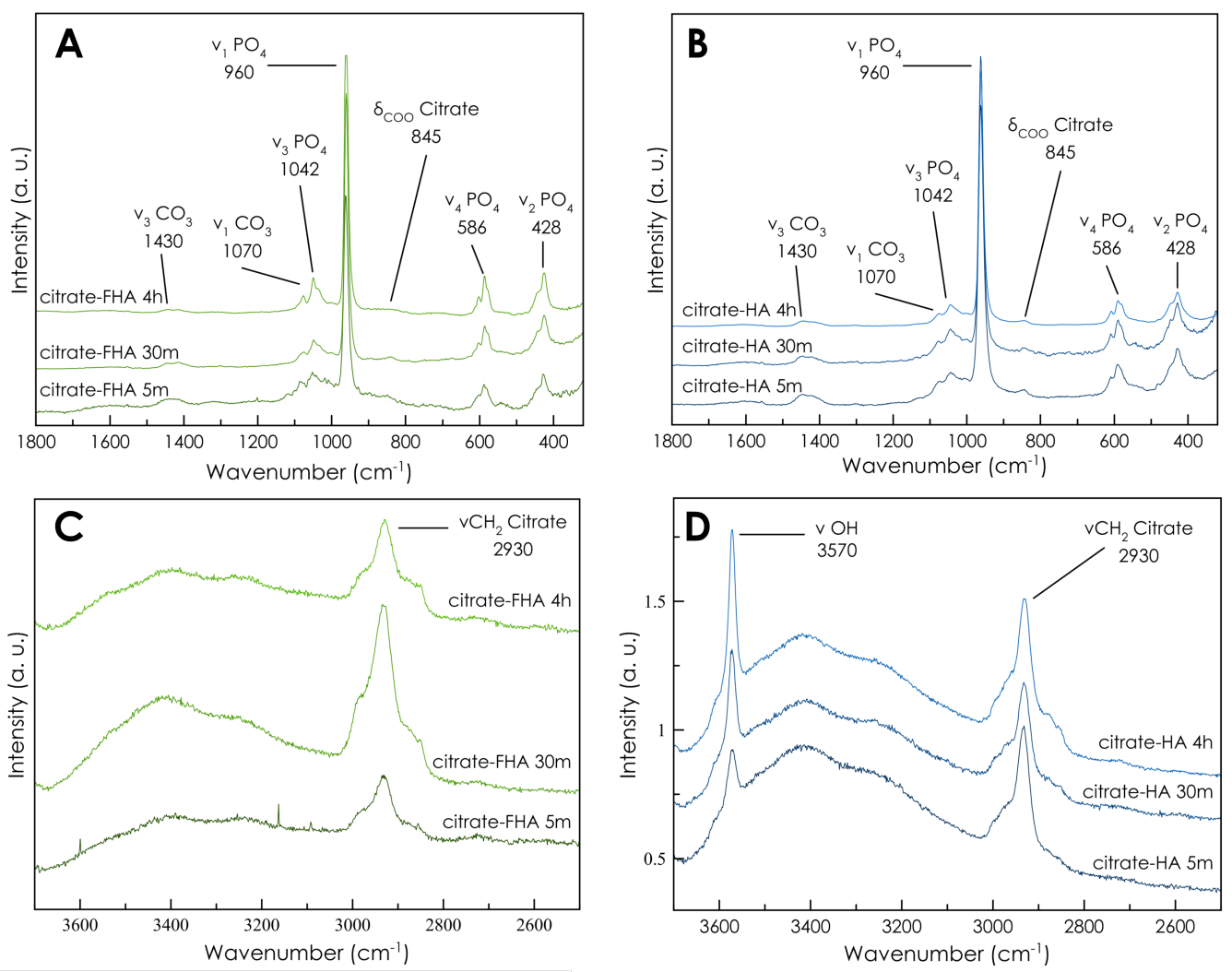

Figure S5. Raman spectra of (A) of citrate-FHA 5m, citrate-FHA 30m, citrate-FHA $4 \mathrm{~h}$ and (B) citrate-HA 5m, citrate-HA 30m, and citrate-HA 4h. (C) and (D) show an enlarged view of the $\mathrm{OH}$ and $\mathrm{CH}$ stretching modes spectral region for citrate-FHA and citrate-HA, respectively. 
FT-IR spectroscopy in controlled atmosphere mode (Figure S6). The $v$ asymCOO mode of citrates falling in $1750-1500 \mathrm{~cm}^{-1}$ range overlaps with $\delta \mathrm{H}_{2} \mathrm{O}$ mode of adsorbed water (centered at ca. $1645 \mathrm{~cm}^{-1}$ ). Thus, the detailed analysis of citrate profile requires the complete removal of the adsorbed water. To this aim, the sample in contact with $\mathrm{H}_{2} \mathrm{O}$ at 20 mbar (curve a) was outgassed at b.t. for 60 min (curve b). Further, surface-accessible water along with $\mathrm{OH}$ species was exchanged with $\mathrm{D}_{2} \mathrm{O}\left(\delta \mathrm{D}_{2} \mathrm{O}\right.$ is located at $\left.1200 \mathrm{~cm}^{-1}\right)$ by 10 cycles of contacting the sample with 20 mbar of $\mathrm{D}_{2} \mathrm{O}$ for $5 \mathrm{~min}$ followed by $5 \mathrm{~min}$ outgassing with subsequent 60 min outgassing at b.t. (curve c). The resulting profile is 'cleaned' from the contribution of water vibrations in the 1750-1500 $\mathrm{cm}^{-1}$ range.

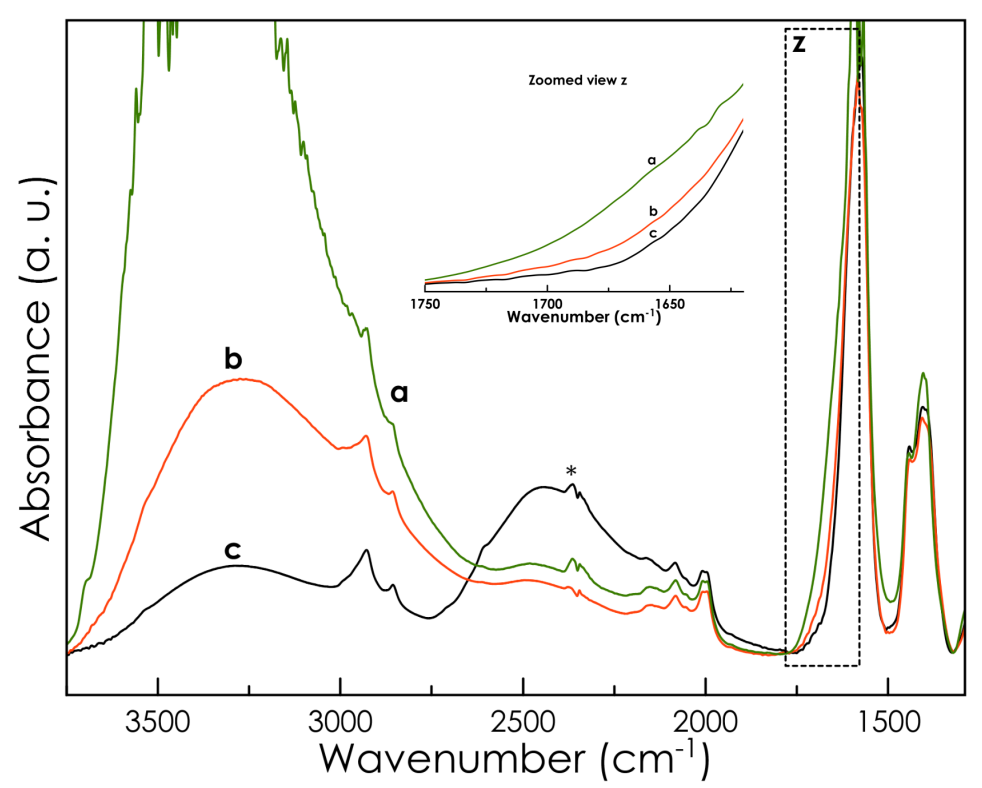

Figure S6. FT-IR spectra of citrate-FHA 4h. Curve (a) in contact with $\mathrm{H}_{2} \mathrm{O}$ vapor at 20 mbar; curve (b) after 60 min outgassing at b.t.; curve (c) after exchange with $\mathrm{D}_{2} \mathrm{O}$ and subsequent 60 min outgassing at b.t. Inset: zoomed view of $1750-1620 \mathrm{~cm}^{-1}$ range. *small feature due to noncompensated atmospheric $\mathrm{CO}_{2}$. 

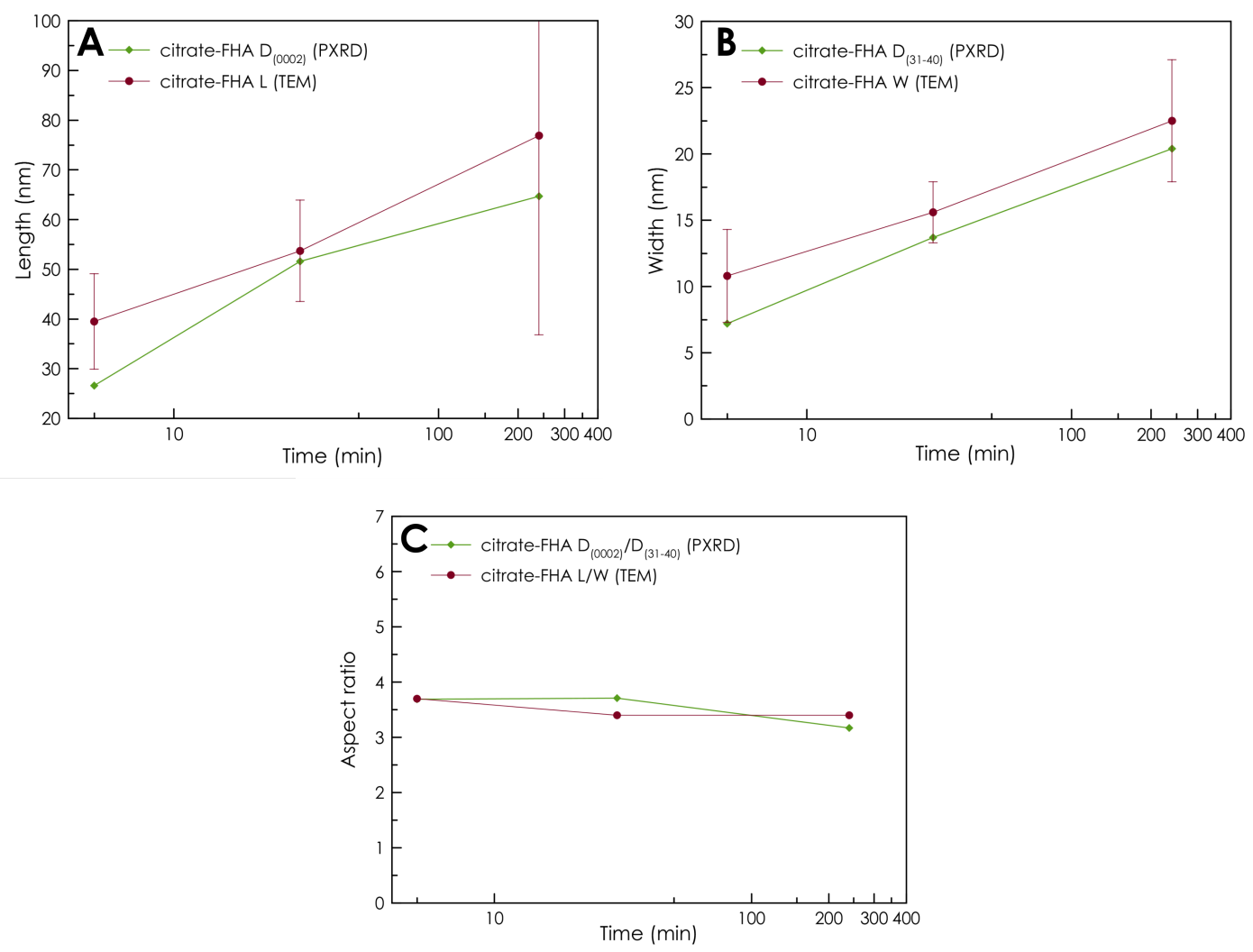

Figure S7. Plot as a function of the maturation time of (A) length, (B) width, and (C) aspect ratio of citrateFHA nanoparticles evaluated by TEM. A comparison with the respective crystal domains calculated by PXRD patterns is reported in each panel.
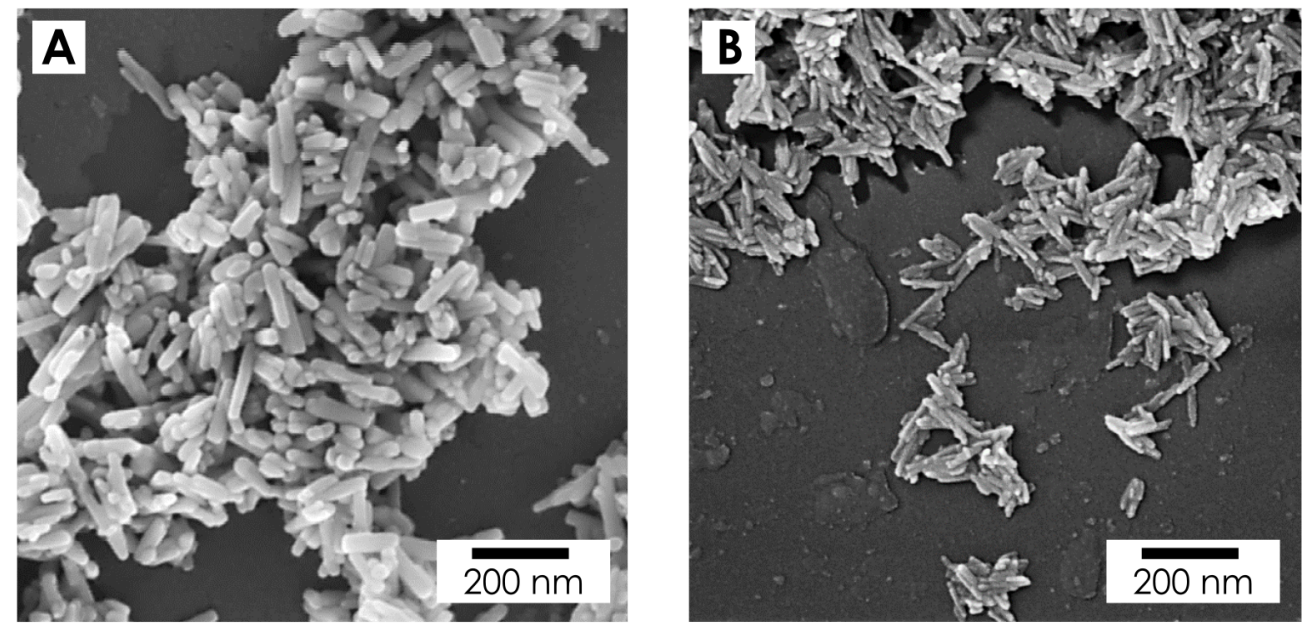

Figure S8. FEG-SEM micrographs of (A) citrate-FHA 4h, and (B) citrate-HA 4h. 

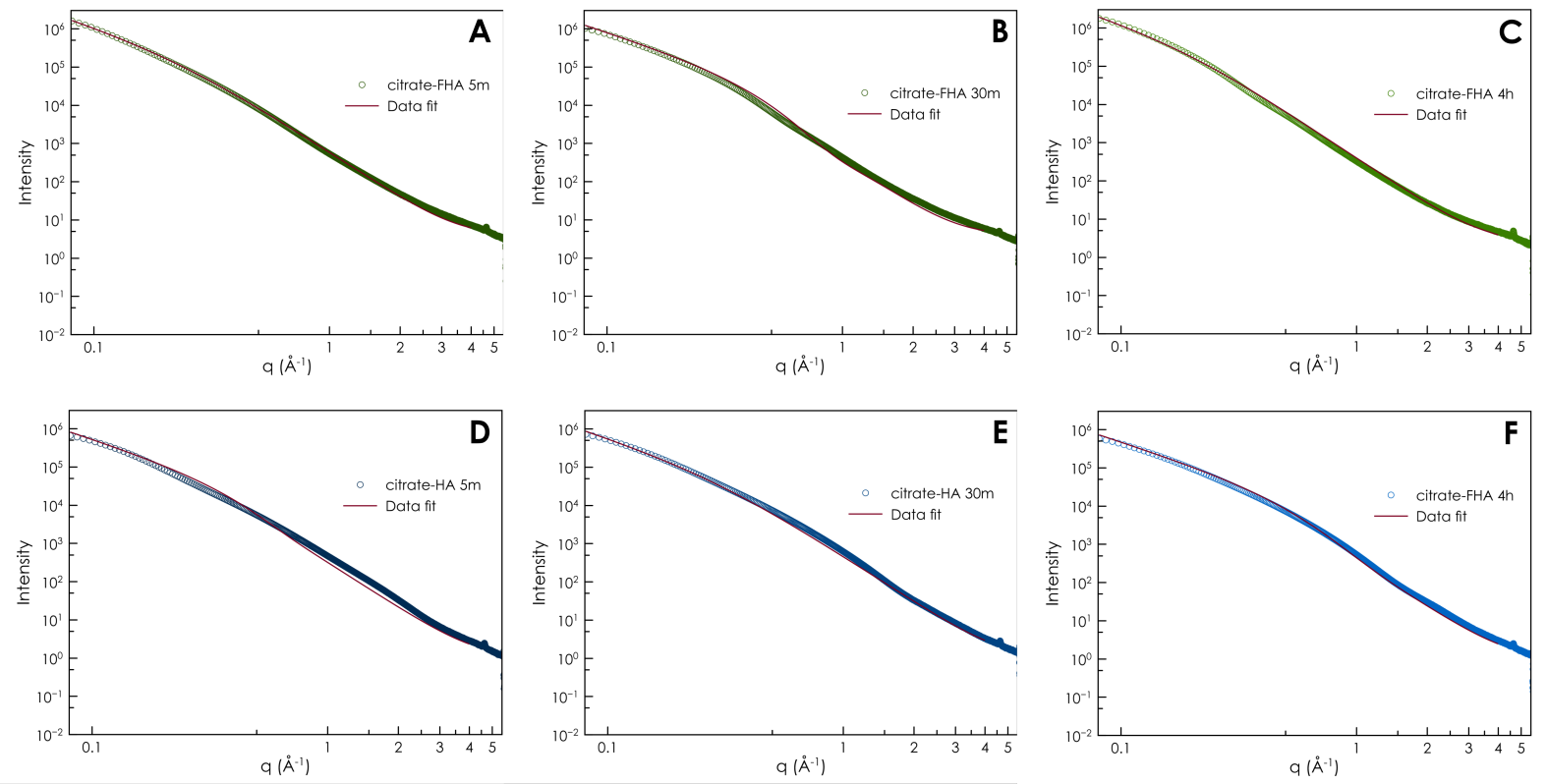

Figure S9. SAXS curves and data fitting with lamellar model for (A) of citrate-FHA 5m, (B) citrate-FHA 30m, (C) citrate-FHA 4h, (D) of citrate-HA 5m, (E) citrate-HA 30m, and (F) citrate-HA 4h.

Table S3. Mean thickness and polydispersity of citrate-HA samples extracted as lamellar model fitting SAXS data.

\begin{tabular}{ccc}
\hline Sample & Thickness (nm) & Polydispersity \\
\hline Citrate-HA 5m & 6,8 & 0,47 \\
Citrate-HA 30m & 7,1 & 0,70 \\
Citrate-HA 4h & 5,5 & 0,30 \\
\hline
\end{tabular}

\section{References}

1. Koutsopoulos, S., Synthesis and characterization of hydroxyapatite crystals: a review study on the analytical methods. Journal of Biomedical Materials Research: An Official Journal of The Society for Biomaterials, The Japanese Society for Biomaterials, and The Australian Society for Biomaterials and the Korean Society for Biomaterials, 2002. 62(4): p. 600-612.

2. Antonakos, A., E. Liarokapis, and T. Leventouri, Micro-Raman and FTIR studies of synthetic and natural apatites. Biomaterials, 2007. 28(19): p. 3043-3054.

3. Tonsuaadu, K., et al., A review on the thermal stability of calcium apatites. Journal of Thermal Analysis and Calorimetry, 2011. 110(2): p. 647-659.

4. Socrates, G., Infrared and Raman characteristic group frequencies: tables and charts. 2004: John Wiley \& Sons. 